\title{
Factors Associated with Participation in Stool Based Colorectal Screening in Brunei Darussalam
}

\author{
Vui Heng Chong1,2,3*, Lydiana Kadir ${ }^{4}$, Zakaria Kamis ${ }^{4}$, Norhayati Kassim ${ }^{4}$, \\ Muhammad Abdul Mabood Khalil ${ }^{5}$, Jackson Tan ${ }^{3,5}$, Elvynna Leong ${ }^{6}$, Sok King \\ Ong $^{7}$, Chee Fui Chong 5
}

\begin{abstract}
Introduction: Colorectal cancers (CRC) continues to increase worldwide and is associated with significant morbidity and mortality. CRC can be prevented through early detection using several modalities. However, like any screening program participation remains suboptimal. This study assessed the factors associated with participation in a stool based CRC screening that was carried out as part of an Integrated Health Screening Survey for civil servants. Materials and Methods: Civil servants who participated in a health survey $(\mathrm{N}=10,756$, mean age $48.08 \pm 5.26$ years old $)$ were studied. Demographic factors (gender, age groups, marital status, employment status, body mass index [BMI] categories, smoking status, personal and family history of cancers) were analyzed to assess for features associated with willingness to participate in this fecal immunohistochemistry test (FIT) screening for CRC. Comorbid conditions studied were cardiac disease, diabetes mellitus, dyslipidemia, hypertension and stroke. Multivariate analysis was performed to evaluate variables associated with participation in CRC screening programme. Results: Of the invited 10,756 participants, 7,360 returned a stool specimen giving a participation rate of $68.4 \%$. Those who participated were significantly older $(<40$ [41.3\%], 40-44 [64.6\%], 45-49 [68.8\%], 50-54 years [70.6\%], 55-59 years [72.4\%] and $>60$ years [77.8\%], $p<0.001$ for trend), being of professional employment $(\mathrm{p}=0.010)$ and presence of comorbid conditions $(\mathrm{p}=0.003)$. There were no significant differences between gender, race, marital status, BMI categories, personal history of cancer, family history of cancer, and smoking status (all p values $>0.05)$. Multivariate analyses showed that older age (45-49, 50-54, 55-59 and >60) and employment status (professional) remained significant factors associated with participation in a stool based CRC screening. Conclusions: Our study showed that older age and professional employment status were significantly associated with willingness to participate in a stool based CRC screening.
\end{abstract}

Keywords: Colorectal cancer- screening, participation- prevention- stool occult blood

Asian Pac J Cancer Prev, 21 (8), 2231-2236

\section{Introduction}

Worldwide, the overall incidence of colorectal cancer (CRC) is increasing, however the incidence rates are plateauing and even declining in some of the developed nations (IARC, GLOBOCAN, 2012) whereas in the developing nations, the incidence continue to increase. These increases have been attributed to the ageing population, change in diet and change in lifestyle, in particular sedentary lifestyles (Jemal et al., 2011; Miller et al., 2016). The plateauing and declining trends seen in some of the developed nations have been attributed to the CRC screening programs either regional or nationally that have been implemented for many years.

As CRC takes between five to ten years to develop, screening allows early detection of CRC in the early stages or colorectal neoplasms in the non-malignant stages, hence preventing progression to CRC. This translate to better treatment outcome, patient prognosis and in the long-term reduction in the incidence of CRC. Screening has been shown to be associated with CRC prevention and also reduction in CRC mortality (Moore \& Aulet, 2017; Lauby-Secretan et al., 2018). Screening can be carried out using several modalities; stool based fecal occult blood testing, sigmoidoscopy and colonoscopy (Sung et al., 2015; Rex et al., 2017; Wolff et al., 2018). The most widely used CRC screening modalities are stool based test and endoscopy, either alone or in combination.

Despite the effectiveness of screening in the prevention and early detection of $\mathrm{CRC}$, the participation rates for

${ }^{1}$ Department of Medicine, RIPAS Hospital, Brunei Darussalam. ${ }^{2}$ Department of Medicine, PMMPHAMB Hospital, Brunei Darussalam. ${ }^{3}$ PAPRSB Institute of Health Science, Universiti Brunei Darussalam, Brunei Darussalam. ${ }^{4}$ Health Promotion Centre, Ministry of Health, Brunei Darussalam. ${ }^{5}$ RIPAS Hospital, Bandar Seri Begawan, Brunei Darussalam. ${ }^{6}$ Universiti Brunei Darussalam, Brunei Darussalam. 'Public Health Services, Ministry of Health Brunei Darussalam. *For Correspondence: chongvuih@yahoo.co.uk 
CRC screening program remain suboptimal regardless of the modalities used (Chen et al., 2019; Hong et al., 2019; Moutel et al., 2019). This is also the case for screening of other cancers (Suh et al., 2017). Reported factors associated with low participations rate include younger age, male, lack of continuity to care, lack of a close relationship or continuous connection between the physician, potential inconveniences associated with the screening tests, policy changes insufficiently publicized prior to implementation to minimize confusion; barriers to cancer screening faced by individuals of low socioeconomic status includes lack of time, lack of knowledge, physical disability or underlying disease, and logistic barriers. However, participations tended to improve over time (Suh et al., 2017). To date there is no data available from our country on participation rate in CRC screening where the incidence of CRC continue to increase (Chong et al., 2009; Mohammad et al., 2014). The aim of this study is to assess the factors that are associated with participation in a stool based CRC screening that was carried out as part of an Integrated Health Screening for civil servants in Brunei Darussalam.

\section{Materials and Methods}

Patient Population: This study was a retrospective analysis of data collected from a health screening study (Integrated Health Screening Study). During the period from 2008 to 2013 , civil servants were invited to participate in this health screening study. There were a total of 49,760 civil servants who were invited of which $21,438(43.1 \%)$ had completed a health questions survey. Of this, 10,756 (21.6\%) participated in this stool based FIT CRC screening. All civil servants during the study period were invited through cooperation with the various ministries, and participations where voluntary. Selected participants were invited through schedule appointment slots for assessment and also given the questionnaire to complete. The questionnaire included demographic data (age, gender, race, employment status, comorbidities specifically ischemic heart disease, diabetes mellitus, hyperlipidemia, hypertension and stroke, and history of cancer; personal and family) and personal history of cancers, lifestyle and also investigations for screening of common Non-communicable diseases (NCDs) such as hypertension, dyslipidemia, diabetes mellitus and ischemic heart disease. For the CRC screening, all participants who were 40 years or above were invited to do a single sample stool based screening using FIT (fecal immunohistochemistry test). However, younger participants were also included in the screening program upon request or if they had additional risk factors such as family history of cancer. Instruction on stool specimen collections were given to all subjects (verbal and writing) and participants were instructed to return the specimens the following day directly to the central laboratory or the nearest hospital which were then dispatched to the central laboratory. All returned stool specimens were processed in the central laboratory following the FIT kit's instruction. All the results of the FIT results were returned to the screening coordinating center (Health Promotion Centre,
Ministry of Health) for data entry and tabulations.

Data collected were entered in the Microsoft Excel database and identifying details were removed for anonymity. The study was conducted following the recommendation of the Declaration of Helsinki.

Definitions: In our setting, employment status was categorized into different divisions and this correlates with seniority and pay-scale grades. Employment is divided into five divisions; Division I - professionals with the highest range pay grade (i.e. Directors and above, doctors with higher professional qualifications, higher educational institution lecturers etc); II - Professionals (i.e. Doctors without higher professional qualification, education officers, etc); III - Assistants, Clericals etc IV - Clerical, Technicians and non-professionals; and $\mathrm{V}$ - non-professional laborers. Any participants who reported a history of cancers were required to provide information on whether the reported cancers were personal history or self-reported family history or combination. Participants who responded with unsure responses about history of cancers and comorbid conditions were categorized as absence or negative.

Statistical analyses: Descriptive statistics were used and data were presented as absolute number and percentage. Continuous variables were presented as mean and standard deviation. For univariate analyses, the ChiSquare test was used to compare the categorical variables. A $p$ value of less than 0.05 on univariate analyses was taken as significant and entered in multivariate logistic linear regression analysis to assess for variables predictive of participation in this stool based FIT CRC screening. The IBM SPSS Statistics 22 software was used for analyses.

\section{Results}

Of the 10,756 participants who were invited, 7,360 returned their stool specimens giving a participation rate of $68.4 \%$. The mean age of the participants was $48.08 \pm 5.26$ years, most were Malays, married and non-professional employment consistent with the makeup of the civil servants' population. There was almost equal gender breakdown. The majority of the participants were overweight with a mean body mass index of $27.38 \pm$ $4.93 \mathrm{~kg} / \mathrm{m} 2$. Comorbidities (hypertension, dyslipidemia, diabetes mellitus and ischemic heart disease) were reported by $36.9 \%$ of participants. The demographic of participants is shown in Table 1.

Overall, $10.4 \%(n=1,118)$ of participants were positive for self-reported history of cancers; personal history only $(n=78,0.7 \%)$, family history cancers only $(n=1,020,9.5 \%)$ with a proportion 20 participants $(0.2 \%)$ reported both personal and family history of cancers.

On univariate analyses, patient of older age groups $(p<0.001$ for trend), being in professional employments $(p=0.010)$ and having any comorbid conditions $(p=0.003)$ showed significant association. However, none of the individual comorbid conditions were associated with willingness to participate. There was a trend towards significance for racial group $(\mathrm{p}=0.076)$ and marital status $(p=0.075)$. There were no significant associations with either personal or family history of cancers. This is shown 
DOI:10.31557/APJCP.2020.21.8.2231

Factors Associated with Participation in Stool Based Colorectal Screening in Brunei Darussalam

Table 1. Demographic of Participants in the FIT Study $(\mathrm{N}=10,756)$

\begin{tabular}{|c|c|}
\hline Variables & Mean (SD) \\
\hline \multicolumn{2}{|l|}{ Age groups (years) } \\
\hline$<40$ & $250(2.3)$ \\
\hline $40-44$ & $2,694(25.0)$ \\
\hline $45-49$ & $3,582(33.3)$ \\
\hline $50-54$ & $3,198(29.7)$ \\
\hline $55-50$ & $825(7.7)$ \\
\hline$>60$ & $198(1.8)$ \\
\hline Missing data & $9(0.1)$ \\
\hline \multicolumn{2}{|l|}{ Gender } \\
\hline Male & $5,058(47.0)$ \\
\hline Female & $5,698(53.0)$ \\
\hline \multicolumn{2}{|l|}{ Race } \\
\hline Malay & $9,845(91.5)$ \\
\hline Others & $851(7.9)$ \\
\hline Missing data & $60(0.6)$ \\
\hline \multicolumn{2}{|l|}{ Marital status } \\
\hline Married/Separated & $9,489(88.2)$ \\
\hline Single & $944(8.8)$ \\
\hline Missing data & $323(3.0)$ \\
\hline \multicolumn{2}{|l|}{ Employment } \\
\hline Divisions I/II & $1,685(15.7)$ \\
\hline Divisions III/IV/V & $8,575(79.7)$ \\
\hline Missing data & $496(4.6)$ \\
\hline \multicolumn{2}{|l|}{ Comorbidities } \\
\hline Yes & $3,974(36.9)$ \\
\hline No & $6,695(62.2)$ \\
\hline Missing data & $87(0.8)$ \\
\hline \multicolumn{2}{|l|}{ Smoking status } \\
\hline Active/past smoker & $1,944(18.1)$ \\
\hline Never & $8,812(81.9)$ \\
\hline \multicolumn{2}{|l|}{ BMI categories $(\mathrm{N}=10,601)$} \\
\hline Underweight & $169(1.6)$ \\
\hline Normal & $3,271(30.9)$ \\
\hline Overweight & $4,523(42.7)$ \\
\hline Obese & $2,638(24.9)$ \\
\hline Personal history of cancer & $98(0.9)$ \\
\hline Family history of cancer & $1,040(9.7)$ \\
\hline
\end{tabular}

Racial group, Other consisted of Chinese $(n=322)$, Indigents $(n=2)$ and expatriate workers ( $\mathrm{n}=527)$; Employment division (Divisions I/II: professionals, III/IV: clerical and V: laborer)

in Table 2.

On multivariate analyses, age and employment status (being professional; divisions I or II) were independently associated with participation (Table 3). Those younger than 44 years was found to be about 1.2 to 7.5 times less likely to participate compared to those over 60 years old. Those with employment status of division I/II representing professionals were more likely to participate compared to those in division III/IV/V (OR: 0.866 of not returning stool sample). Presence of any of the defined comorbid
Table 2. Univariate Analyses of Factors Predictive of Participation in a Single FIT CRC Screening

\begin{tabular}{|c|c|c|c|}
\hline \multirow[t]{3}{*}{ Variables } & \multirow{2}{*}{\multicolumn{2}{|c|}{$\begin{array}{c}\mathrm{n}(\%) \\
\text { Participation }\end{array}$}} & \multirow[t]{3}{*}{$P$-values } \\
\hline & & & \\
\hline & Yes & No & \\
\hline \multicolumn{4}{|l|}{ Age groups (years) } \\
\hline$<40$ & $38(41.3)$ & $54(58.7)$ & \multirow{6}{*}{$\begin{array}{c}<0.001 \\
\text { for trend }\end{array}$} \\
\hline $40-44$ & $1,842(64.6)$ & $1,010(35.4)$ & \\
\hline $45-49$ & $2,465(68.8)$ & $1,117(31.2)$ & \\
\hline $50-54$ & $2,259(70.6)$ & $939(29.4)$ & \\
\hline $55-59$ & $597(72.4)$ & $228(27.6)$ & \\
\hline$>60$ & $154(77.8)$ & $44(22.2)$ & \\
\hline \multicolumn{4}{|l|}{ Gender } \\
\hline Male & $3,477(68.7)$ & $1,581(31.3)$ & \multirow[t]{2}{*}{0.507} \\
\hline Female & $3,883(68.1)$ & $1,815(31.9)$ & \\
\hline \multicolumn{4}{|l|}{ Race } \\
\hline Malay & $6,709(68.1)$ & $3,136(31.9)$ & \multirow[t]{2}{*}{0.076} \\
\hline Others & $6.5(71.1)$ & $246(28.9)$ & \\
\hline \multicolumn{4}{|l|}{ Marital status } \\
\hline Married/Separated & $2,969(31.3)$ & 0.075 & \\
\hline Single & $622(65.9)$ & $322(34.1)$ & \\
\hline \multicolumn{4}{|l|}{ Employment } \\
\hline Divisions I/II & $1,195(70.9)$ & $490(29.1)$ & \multirow[t]{2}{*}{0.01} \\
\hline Divisions III/IV/V & $5,808(67.7)$ & $2,767(32.3)$ & \\
\hline \multicolumn{4}{|c|}{ Presence of comorbidities * } \\
\hline Yes & $2,785(70.1)$ & $1,189(29.9)$ & \multirow[t]{2}{*}{0.003} \\
\hline No & $4,504(67.3)$ & $2,191(32.7)$ & \\
\hline \multicolumn{4}{|l|}{ Smoking status } \\
\hline Active/past smoker & $1,301(66.9)$ & $643(33.1)$ & \multirow[t]{2}{*}{0.115} \\
\hline Never & $6,059(68.8)$ & $2,753(31.2)$ & \\
\hline \multicolumn{4}{|c|}{ BMI categories $(\mathrm{N}=10,601)$} \\
\hline Underweight & $113(66.9)$ & $56(33.1)$ & \multirow{4}{*}{$\begin{array}{l}0.629 \text { for } \\
\text { trend }\end{array}$} \\
\hline Normal & $2,266(69.3)$ & $1,005(30.7)$ & \\
\hline Overweight & $3,104(68.6)$ & $1,419(31.4)$ & \\
\hline Obese & $1782(67.6)$ & $856(32.4)$ & \\
\hline \multicolumn{4}{|l|}{ Personal history of cancer } \\
\hline Yes & $70(71.4)$ & $28(28.6)$ & \multirow[t]{2}{*}{0.521} \\
\hline No & $7,290(68.4)$ & $3,368(31.6)$ & \\
\hline \multicolumn{4}{|l|}{ Family history of cancer } \\
\hline Yes & $732(70.4)$ & $308(29.5)$ & \multirow[t]{2}{*}{0.153} \\
\hline No & $6,628(68.2)$ & $3,088(31.8)$ & \\
\hline
\end{tabular}

*comorbidities, hypertension, ischemic heart disease, diabetes mellitus, hyperlipidemia and stroke Missing data

conditions was not significant $(\mathrm{p}=0.054)$.

\section{Discussion}

This study reported a screening uptake rate of $68.4 \%$ from a single FOB based CRC screening program that was conducted as part of a more comprehensive screening survey looking at NCDs. The high uptake rate was contributed by the fact that the target group was civil servants, and there were established cooperation between ministries. However the rate cannot be compared to national screening program uptake rates which are 
Table 3. Multivariate Analyses of the Factors Predictive of Non-Participation in This Stool based CRC Screening

\begin{tabular}{lccc}
\hline Variables & Odd ratio\# & $\begin{array}{c}\text { P- } \\
\text { value }\end{array}$ & $\begin{array}{c}95 \% \text { Confidence } \\
\text { interval }\end{array}$ \\
\hline $\begin{array}{l}\text { Age groups } \\
\quad<40\end{array}$ & 4.26 & $<0.001$ & 2.422 to 7.495 \\
$40-44$ & 1.726 & 0.004 & 1.188 to 2.508 \\
$45-49$ & 1.453 & 0.049 & 1.001 to 2.108 \\
$50-54$ & 1.315 & 0.150 & 0.905 to 1.911 \\
$55-59$ & 1.29 & 0.208 & 0.868 to 1.918 \\
$>60 *$ & & & \\
Division & & & \\
$\quad \begin{array}{l}\text { Division I/II } \\
\text { Division III/IV/V* }\end{array}$ & 0.866 & 0.015 & 0.772 to 0.972 \\
Presence of comorbidities & & \\
$\quad$ Yes & 1.091 & 0.054 & 0.998 to 1.191 \\
$\quad$ No* & & & \\
\hline
\end{tabular}

Division, levels of employment in the government services: Divisions I and II; professionals employment requiring minimal tertiary educations; and Divisions III/IV/V: professions such as assistants, clerk, technicians and laborers requiring minimal secondary or primary educations. *, reference group for comparison; \#, Odds Ratio represents Likelihood of not participating in the program.

expected to be lower. In South Korea where the National Cancer Screening Program (NCSP) has been in place since 1999 that included screening for several cancers reported a $39.5 \%$ uptake of CRC screening based on FOB screening (Suh et al., 2017). The uptake was less than $10 \%$ in 2004 but slowly increased to $39.5 \%$ in 2012 , at a rate of $4 \%$ per year. Participation for other cancers screening such as stomach $(47.3 \%)$, liver $(25.0 \%)$, breast $(51.9 \%)$, and cervix $(40.9 \%)$ were also suboptimal but showed increasing trends (Suh et al., 2017). In the Netherland, the uptake for FOB screening was 50\% (Wieten et al., 2019). However, participation rates was high in a study by the Veteran Affairs with CRC screening rate of $81.5 \%$, where the target group of screening were the veterans whose healthcare are covered by the Veteran Health Administration (May et al., 2019). Generally uptake also depends on the screening modality used.

Several reasons may account for the relatively high participation rate in our study. First, our program only utilized a single stool sample which was simple and required less interruption or requirement from the participants' point of view. Second, being part of a program carried out by employer, in our case civil service may have resulted in participants feeling obligated to participate even though participations were voluntary. Alternatively it was possible that participants had simply taken advantage of having a comprehensive medical check.

Generally the more complex a program is or as screening process proceed, subsequent participations are expected to decline. People may participate at the initial stage but they may not be inclined to proceed especially if further testing may impose on their daily schedules, especially if they are well and asymptomatic. This is also the case in our experience. We previously reported on the yield of this single FOB based CRC screening (Chong et al. 2014). The overall FOB positivity rate was $1.9 \%$ and all these participants including those with family history or previous personal history of colorectal neoplasms were referred for screening colonoscopy. Of those referred only a disappointing $17.7 \%$ attended follow-up appointments and of these, only half proceeded for screening colonoscopy (Chong et al., 2014). The main reason for declining the offer of colonoscopy was that they were well and asymptomatic, similar to what have been reported in the literature (Park et al., 2012). Some participants with positive FIT test requested for repeated testing and subsequently declined colonoscopy when the retest came back as negative (Chong et al., 2014). However, many of the participants already had screening done (mainly for family history of CRC) outside of this health survey did not participate. In Denmark, non-participations for screening colonoscopy following positive FOB were $10.65 \%$ and $11.37 \%$ for men and women respectively (Deding et al., 2019), much lower than our experience. Another study in the United States reported follow-up participation after positive initial screen of CRC of 76.3\% (Barlow et al., 2019). Studies have shown that screening with colonoscopy had better uptake and increasingly being used compared to stool based CRC screening program (Guo et al., 2019). Stool based screening needs to be repeated annually or biannually whereas colonoscopy need not be repeated for ten years if the initial colonoscopy was normal. A study in Spain showed that with continued screening, the participation rate for stool based declined with time (Benito et al., 2019). They showed that uptake of FIT and guaiac FOBT (gFOBT) of $37.4 \%$ and $23.9 \%$ respectively and overall rate consistently screened invitees after seven rounds to be only $14.2 \% ; 20.6 \%$ for FIT and $14.3 \%$ with gFOBT. This show that as time progress, continued participations by the previous participants tended to decline.

Factors reported to be associated with non-participations of CRC screening programs regardless of the primary modalities used (usually stool based as primary) included older age, lower income, lower educational level, immigrants, being singles, lack of insurance coverage, obesity, smoker and living in the rural area (Guo., et al 2019; Deding et al., 2019, Goodwin et al., 2019). In our study, being older and of professional employment (divisions I and II) were associated with willingness to participate. As the age increased the proportion of participations increased from $41.3 \%$ in the $<40$ years group to $77.8 \%$ in the $>60$ years group. On multivariate analysis, younger participants specifically the $<40$, 40-44 and 45-49 years groups were associated with non-participation compared to the older age group. However it has also been shown that older people, much older than our participants are less likely to participate (Deding et al., 2019). Therefore, there may be an inverted U-shape curve in the age factor where only those at certain ages are more inclined to participate. In our study, our participants were active civil servants and were 
generally younger than 60 years old, the official retirement age in Brunei Darussalam. If we had included older population, the participation rate may be lower. Being of professional employment is generally a reflection of the educational background and hence literacy level, and health awareness. In our questionnaire previous study, we showed that the level of awareness and knowledge of CRC were better among those with higher level education in additional to female gender and non-Malay racial groups. Despite this level of awareness even among those with tertiary educations was suboptimal (Chong et al., 2015). This has also been shown in other countries (Koo et al., 2012). Uptake for screening colonoscopy has been shown to be suboptimal even among doctors but much higher than non-doctor general population (uptake rates 34.2\% and $6.2 \%$ respectively) (Viazis et al., 2019).

In our study having any comorbid conditions in particular NCDs was significant on univariate analysis but not on multivariate analyses $(\mathrm{p}=0.054)$. One would expect having any comorbid conditions may make participants more health conscious and would also mean that these participants would have had multiple healthcare encounters, and would be more likely to have receive some form of health educations or advices. In our study we only looked at specifically comorbidities categorized as NCDs and is unknown if the results would have been different if we had included all chronic conditions. It is interesting to note that history of self-reported personal or family history of cancers were not associated with willingness to participate. One possible explanation could be that there may be recall biases in self-reporting data and the small sample size of participants with history of cancers. Furthermore, some of the patients who had either personal or family history of cancer may already have had screening done prior to this study and under follow up of their respective doctors.

In any screening program it is important that the participations are maximized. Therefore, a program has to be easy to participate at the start and as the process proceed. Issues and possible barriers to participations needs to be identified before any screening programs is planned and implemented. Among the screening modalities for CRC; colonoscopy (38.4\%) as the primary modality has been shown to have the highest participation rates compared to stool (FIT) based $(28.0 \%)$ or usual care $(10.7 \%)$ with better completion screening rate (Singal et al., 2017). However a study in the Netherland showed better uptake for stool based (guaiac based $49.5 \%$ and FIT $61.5 \%$ ) compared to flexible sigmoidoscopy (32.4\%) (Hol et al., 2010). Colonoscopy only requires an interval of not more than ten years for those found to be normal at index screening colonoscopy. However colonoscopy will be much more labor intensive and costly. Stool based strategy is the most widely used but test needs to be repeated every few years depending on the interval decided for a program commonly either annually or biannual. Additional measures such as reminder (i.e. telephone follow up reminder), primary care physicians' participations (Dodd et al., 2019), better coverage and public education have been shown to improve participation rates.

There are several limitations with our study. First; we acknowledge that the Integrated Health Survey was done quite some time ago. However, we believe that our data remain valid and are still representative of the population studied which consisted exclusively of civil servants. Given that recruitment and retirement age for government services had remained unchanged, the population pyramid and profiles would have largely remained similar or unchanged. Second, as this study only involved civil servants, our findings cannot be extrapolated to the general population which include those retired or those working in the private sectors where there may be other restrictions. Third, our stool based screening program is based on a single stool sample. The result may be different if more than one stool sample is required or different modalities were used. Fourth, the small sample size of participants with self-reported history of cancers may have affected the result given that a history of cancer would have expected to push participants to participate in screening. Finally being a questionnaire study, there may be recall biases in the self-reporting of the cancer history. Despite all these, our study will be valuable to serve as a baseline for future comparisons nationally and also comparisons with other countries.

In conclusion, our study showed that participation rate of invited civil servants in this Integrated Health Screening Survey for a stool based CRC screening was good. The factors associated with participation were older age and professional employment status. Interestingly the presence of self-reported history of cancers; either personal or family were not significant. Further studies should be undertaken to understand more the reasons for nonparticipation in CRC screening program and these reasons may be unique to a locations. Furthermore, they may be also relevant to other screening programs. Such knowledge will allow changes to be made to enhance and maximize participations. Steps should also be taken to monitor the level of participations once the screening program starts. A screening program can only be successful with maximal participation.

\section{Acknowledgements}

The Integrated Health Screening Team Nelson Dennis, Norhaslinda Hj Panjang, Ak Ihsanuddin Pg Hj Ali, Nur Shawarni Shahrul Mazlan, Hjh Siti Azelah Hj Abd Karim, Hassanawati $\mathrm{Hj}$ Bagol, Hjh Rusitah Hj Besar, Alina Hj Abdullah, Low Meng Kuan, Hjh Nipah Hj Hasan, Pg Hjh Aji Pg Hj Kula, Raffiah Hj Hassan, Rabiatul Adawiyah Abdullah, Noradyaniwati Isamail, Raffidah PDR Hj Hamid, Nurol Hazdillah Hj Ahmad, Mardiana $\mathrm{Hj}$ Mohamed and Eda Lydiawati $\mathrm{Hj}$ Ahmad.

No funding was required for the study. The study was conducted in accordance with the Declaration of Helsinki. All identifying details had been removed and dataset was anonymized before analyses. None of the authors declare any conflict of interest.

\section{Authors' involvements}

VHC, ZK conceived the idea of the study. LK, ZK, NK were curators of anonymized data. VHC, CFC and EL analyzed the data. VHC draft the initial draft and all 
authors (LK, ZL, NK, MAMK, JT, EL, SKO and CFC) critically reviewed the draft. VHC revised and all authors (LK, ZL, NK, MAMK, JT, EL, SKO and CFC) approved the final manuscript.

\section{References}

Barlow WE, Beaber EF, Geller BM, et al (2019). Evaluating screening participation, follow-up and outcomes for breast, cervical and colorectal cancer in the PROSPR consortium. J Natl Cancer Inst, 2019, pii: djz137.

Benito L, Travier N, Binefa G, et al (2019). Longitudinal adherence to immunochemical fecal occult blood testing vs guaiac-based FOBT in an organized colorectal cancer screening program. Cancer Prev Res (Phila), 12, 327-34.

Chen H, Li N, group of Cancer Screening Program in Urban China (CanSPUC), et al (2019). Participation and yield of a population-based colorectal cancer screening programme in China. Gut, 68, 1450-7.

Chong VH, Lim AG, Baharudin HN, Tan J, Chong CF (2015). Poor knowledge of colorectal cancer in Brunei Darussalam. Asian Pac J Cancer Prev, 16, 3927-30.

Chong VH, Abdullah MS, Telisinghe PU, Jalihal A (2009). Colorectal cancer: incidence and trend in Brunei Darussalam. Singapore Med J, 50, 1085-9.

Chong VH, Bakar S, Sia R, et al (2013). Colorectal cancer screening among government servants in Brunei Darussalam. Asian Pac J Cancer Prev, 14, 7657-61.

Deding U, Henig AS, Hindersson P, Torp-Pedersen C, Bøggild H (2019). Determinants of non-participation in colon examination following positive stool sample in colorectal cancer screening. Eur J Public Health, 2019, pii: ckz072.

Dodd N, Carey M, Mansfield E, Oldmeadow C, Evans TJ (2019). Testing the effectiveness of a general practice intervention to improve uptake of colorectal cancer screening: a randomised controlled trial. Aust N Z J Public Health, 2019, doi: 10.1111/1753-6405.12913. [Epub ahead of print]

Goodwin BC, March S, Ireland M, et al (2019). Geographic variation in compliance with Australian colorectal cancer screening programs: the role of attitudinal and cognitive traits. Rural Remote Health, 19, 4957.

Guo F, Chen C, Schöttker B, et al (2019). Changes in colorectal cancer screening use after introduction of alternative screening offer in Germany: Prospective cohort study. Int $J$ Cancer, 2019, doi: 10.1002/ijc.32566. [Epub ahead of print]

Hol L, van Leerdam ME, van Ballegooijen M, et al (2010). Screening for colorectal cancer: randomised trial comparing guaiac-based and immunochemical faecal occult blood testing and flexible sigmoidoscopy. Gut, 59, 62-8.

Hong S, Shin HY, Lee B, et al (2019). Increase in the colorectal cancer screening rate by a round-mailed fecal immunochemical testing kit and associated factors in underserved regions of Korea: A community-based intervention study. Gut Liver, 2019, doi: 10.5009/gnl19124. [Epub ahead of print]

International Agency for Research on Cancer (IARC). GLOBOCAN 2012. www.globocan.iarc.fr/ (accessed 15 $5^{\text {th }}$ August 2018).

Jemal A, Bray F, Center MM, et al (2011). Global cancer statistics. CA Cancer J Clin, 61, 69-90.

Koo JH, Leong RW, Asia Pacific Working Group in Colorectal Cancer, et al (2012). Knowledge of, attitudes toward, and barriers to participation of colorectal cancer screening tests in the Asia-Pacific region: a multicenter study. Gastrointest Endosc, 76, 126-35.

Lauby-Secretan B, Vilahur N, International Agency for Research on Cancer Handbook Working Group (2018). The IARC perspective on colorectal cancer screening. $N$ Engl J Med, 378, 1734-40.

May FP, Yano EM, Provenzale D, Steers WN, Washington DL (2019). Race, poverty, and mental health drive colorectal cancer screening disparities in the veterans health administration. Med Care, 2019, doi: 10.1097/ MLR.0000000000001186. [Epub ahead of print]

Miller KD, Siegel RL, Lin CC, et al (2016). Cancer treatment and survivorship statistics, 2016. CA Cancer J Clin, 66, 271-89.

Mohammad IA, Bujang MR, Telisinghe PU, et al (2014). Cancers of the young population in Brunei Darussalam. Asian Pac J Cancer Prev, 15, 6357-62.

Moore JS, Aulet TH (2017). Colorectal cancer screening. Surg Clin North Am, 97, 487-502.

Moutel G, Duchange N, Lièvre A, et al (2019). Low participation in organized colorectal cancer screening in France: underlying ethical issues. Eur J Cancer Prev, 28, 27-32.

Park B, Choi KS, Lee YY, Jun JK, Seo HG (2012). Cancer screening status in Korea, 2011: results from the Korean National Cancer Screening Survey. Asian Pac J Cancer Prev, 13, 1187-91.

Redeker C, Wardle J, Wilder D, Hiom S, Miles A (2009). The launch of Cancer Research UK's 'Reduce the Risk' campaign: baseline measurements of public awareness of cancer risk factors in 2004. Eur J Cancer, 45, 827-36.

Rex DK, Boland CR, Dominitz JA, et al (2017). Colorectal cancer screening: Recommendations for physicians and patients from the U.S. Multi-Society Task Force on Colorectal Cancer. Gastroenterology, 153, 307-23.

Singal AG, Gupta S, Skinner CS, et al (2017). Effect of colonoscopy outreach vs fecal immunochemical test outreach on colorectal cancer screening completion: A Randomized Clinical Trial. JAMA, 318, 806-15.

Suh M, Song S, Cho HN, et al (2017). Trends in participation rates for the national cancer screening program in Korea, 2002-2012. Cancer Res Treat, 49, 798-806.

Sung JJ, Ng SC, Asia Pacific Working Group, et al (2015). An updated Asia Pacific Consensus Recommendations on colorectal cancer screening. Gut, 64, 121-32.

Wieten E, de Klerk CM, Lansdorp-Vogelaar I, et al (2020). A quarter of participants with advanced neoplasia have discordant results from 2-sample fecal immunochemical tests for colorectal cancer screening. Clin Gastroenterol Hepatol, 8, 1805-11.

Wolf AMD, Fontham ETH, Church TR, et al (2018). Colorectal cancer screening for average-risk adults: 2018 guideline update from the American Cancer Society. CA Cancer $J$ Clin, 68, 250-81.

Viazis N, Tzouvala M, Theodoropoulou A, et al (2019). Comparison of the Uptake of Screening Colonoscopy between Physicians and the General Population in Greece. Dig Dis, 38, 1-8.

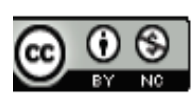

This work is licensed under a Creative Commons AttributionNon Commercial 4.0 International License. 